\title{
An operation optimization method of a fully mechanized coal mining face based on semi-physical virtual simulation
}

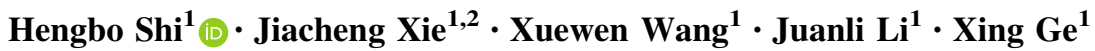

Received: 29 August 2019/Revised: 16 October 2019/Accepted: 1 November 2019/Published online: 2 December 2019

(C) The Author(s) 2019

\begin{abstract}
A mathematical hydraulic support self-tracking model for three-machine cooperative mining is proposed to address low efficiency and difficulties in strategy evaluation of a fully mechanized coal face. The proposed model uses the coordinates and traction speed of the shearer to calculate the frequency of the circular hydraulic support and realize the coordinated operation of the three-machine mining technology. A unity3d hardware-in-the-loop simulation experimental hearer and hydraulic support platform was used to validate the model of autonomous follow-up. The results indicate that collaborative control of coal mining allowed for an efficiency 3.76\% higher than under automatic operation mode and $46.03 \%$ higher than under manual control; thus, The mathematical model provided an improved production efficiency of the fully mechanized mining face. The mathematical model also provides a more intelligent and reliable security support, and improves the intelligent level of hydraulic support follow-up control.
\end{abstract}

Keywords Semi-physical simulation · Virtual reality $\cdot$ Unity3d $\cdot$ Human-computer interaction $\cdot$ Shearer traction speed

\section{List of symbols}

Num Number of moving representatives

$i \quad$ Shearer position measured by the hydraulic support number

$f_{s} \quad$ Shifting frame frequency of the hydraulic support

$t_{1} \quad$ Time of hydraulic support descending column

$t_{2} \quad$ Time of hydraulic support lifting column

$t_{3} \quad$ Time of the stretched of protecting piece of hydraulic support

$V_{q} \quad$ Shearing speed of the shearer

Xuewen Wang

wxuew@163.com

Hengbo Shi

2454348028@qq.com

1 College of Mechanical and Vehicle Engineering, Key Laboratory of Fully Mechanized Coal Mining Equipment, Taiyuan University of Technology, Taiyuan 030024, Shanxi, China

2 Taiyuan Mining Machinery Group Co., Ltd. Postdoctoral Science Research Workstation, Taiyuan 030032, Shanxi, China $d \quad$ Average width of the hydraulic support base

$k_{i} \quad$ Dynamic adjustment factor

$\Delta d \quad$ Average distance between hydraulic supports

$\vec{D} \quad$ Shear's running direction

$S_{t} \quad$ Walking coordinate distance of the shearer along the scraper conveyor

$i_{t} \quad$ Shearer position number relative to the hydraulic support

$i_{c} \quad$ Calculated relative position number of shearer and hydraulic support

$\vec{I} \quad$ Collection of numbers of relative positions between shearer and hydraulic support

$S_{c} \quad$ Calculated shearer distance along the scraper conveyor (calculated by the number of brackets)

$S_{\text {err }} \quad$ Error of $S_{t}$ and $S_{c}$

$i_{\text {err }} \quad$ Error of $i_{c}$ and $i_{t}$

$V_{y} \quad$ Hydraulic support frame speed in working face, $\mathrm{m} / \mathrm{min}$

$K_{c} \quad$ Unbalance factor

$s \quad$ Distance of the moving frame, $\mathrm{mm}$

$Q_{L} \quad$ Flow volumein hydraulic cylinder, $\mathrm{m}^{3} / \mathrm{min}$ 
$k_{f} \quad$ Richness factor of the liquid working conditions, assumed as 2.5 , taking into account the leakage factor, sputum, when adjusting the shelf

$n_{1} \quad$ Pushing jack number

$s_{1} \quad$ Stepping distance of support moving

$F_{1} \quad$ Piston action area in pushing jack rack

$n_{2} \quad$ Column number

$s_{2} \quad$ Height of the lifting and descending columns

$F_{2} \quad$ Piston acting area as the column falls

$F_{3} \quad$ Piston acting area as the column lifts

$N \quad$ Driving power (KW)

$\Delta P \quad$ Pump inlet and outlet pressure (MPa)

$\eta_{t} \quad$ Pump volumetric efficiency

$p_{b} \quad$ Working pressure of the pumping station $\left(\mathrm{N} / \mathrm{m}^{2}\right)$

$F_{1} \quad$ Initial support force of the hydraulic bracket, $\mathrm{N}$

$D \quad$ Inner diameter of the cylinder of the bracket column (m)

$Z \quad$ Number of hydraulic support columns

$F_{\mathrm{n}} \quad$ Maximum thrust of the jack $(\mathrm{N})$

$D_{1} \quad$ Inner diameter of the jack cylinder (m)

\section{Introduction}

The gradual implementation of information technology developments with traditional coal mining technology has allowed for automated, comprehensive mining equipment and unmanned mining.

Although researchers have investigated the motion state of three-machine under the working conditions of a fully mechanized coal mining face, further research is needed regarding the space motion equation and the mathematical model of the hydraulic support following the shearer in time. The production capacity of the equipment cannot also be fully utilized. The application of advanced design methods such as reliability design and finite element analysis has allowed fully mechanized automatic coal mining technology, thus improving mining effectiveness (Ralston et al. 2017a, b). This work presents a self-contained semi-physical collaborative planning simulation system based on Unity3D (Xie et al. 2017, 2018a, b, 2019a) to predict the self-following strategy of this hydraulic support.

Based on the workflow of fully mechanized mining equipment, Zhou (Zhou et al. 2015; Wang et al. 2009, 2013) established collaborative control models of the posture control and comprehensive mining equipment.

Chen et al. (2011) used aPM32 electric hydraulic control system to realize automatic drop, move, and upper support systems, to monitor and display the roof pressure, and to calculate the shearer position, the control of cutting height, and the running speed. This allowed for remote control operation and run, thus improving the level of automation.

Zhang et al. (2014, 2016, 2017) established an overall structure of the system that the hydraulic support can be controlled to follow the shearer automatically, carried out the control system design, and realized the self-regulation of the hydraulic support.

According to control system control requirements, Guo and $\mathrm{Li}$ (2014) achieved a single-frame, single-action, singlerack sequential linkage, group exercise, shearer position detection and overall program design, while the stent control system software and hardware design. Verification has shown that the system was able to achieve basic functions. Reference to automate the development of the growing coal mine hydraulic support electro-hydraulic control system.

Fan et al. (2015) established a constraint model relating the advancing velocity of the hydraulic support and the shearer traction speed through movement analysis, as well as constraint model of the scraper conveyor load and the shearer traction speed based on the scraper conveyor movement collaboratively with the shearer. By characterizing the threemachine as a three-intelligent agent, a coordination system for optimizing the three-machine cooperation was constructed.

Wan et al. (2013) and Li et al. (2015) established virtual shearer, scraper conveyor, and hydraulic support prototypes in a VR environment. Additionally, they established a coordinated movement that was applied in the field of teaching three machines in fully mechanized mining face.

$\mathrm{Li}$ et al. (Xu et al. 2013) introduced and applied a constraint relationship between the coal cutter, scraper conveyor, and hydraulic support in a safe, high-producing, and high-efficient fully mechanized mining face. The composition principle of electro-hydraulic control system, embedded in the hydraulic support, and presented the design scheme of the composition and hardware system about the electro-hydraulic control unit. Their developed scheme allowed for the control and monitoring of the working condition in near real-time, on the ground, in the crossheading, and in front of the mining face.

Zhang and Xiao (2012) established a 3D kinematics model of the hydraulic support using Pro/E software.

Dobrescu et al. (2019) introduced a cloud simulation platform that provided the flexibility to continuously test and update algorithms.

Tichon and Burgesslimerick (2011), Perez et al. (2013), and Pedram et al. (2013) improved miners' safety by applying VR to the safety training drills of miners.

Bednarz et al. (2015) described and demonstrated a framework for human-computer interaction experiments using an immersive virtual reality, computer vision, other sensors, and remote collaboration.

Ma et al. (2014) and Zhang et al. (2016, 2017) developed a general data interface for a virtual control device 
and its implementation method capable of collecting data, updating a database in real-time, and applying the collected console data to virtual reality technology. Furthermore, they established a training method for the virtual training system of the cantilever-type road header.

Küblera et al. (2018) combined test automation with fault injection and proposed a way to implement negative test cases for the test automation framework.

Scheifele et al. (2018) proposed a virtual debug realtime co-simulation platform that integrated powerful technology-specific simulated solutions based on integrated interfaces and real-time based on partitioning, parallelization, synchronization, and data exchange mechanisms. Cosimulation architecture.

The following problems regarding the way in which the three-machine fully mechanized mining technology level is predicted:

(1) a lack of human-computer interaction means.

(2) a lack of a verified mathematical model for use in full-system simulations.

The level of automation of the three machines is gradually improved. In this work, a mathematical model of the autonomous follow-up of hydraulic support is proposed to improve the coal mining efficiency of fully mechanized mining machines. First, the elements of the manufacturing process are digitized in the context of Siemens's digital twin model. Based on this digital model, the production process is simulated to analyze the feasibility of the control and planning strategies of a fully mechanized three-machine mining method.

All elements of the comprehensive mining equipment (Xie et al. 2019b) are digitized to more accurately reproduce the three-machine production process. A mathematical model of autonomous follow-up of hydraulic support based on the running speed of the shearer is also proposed to provide a theoretical basis for the construction of the fully mechanized mining automation, hydraulic support, and linkage model. It provides a theoretical approach for the establishment of an effective coordinated control model for fully mechanized mining equipment. The running state of the entire working surface is reproduced to help coal enterprises test mining strategies in a virtual environment before production, thereby optimizing mining plans and achieving efficient and reliable production (Zhang 2011).

\section{Three-machine comprehensive mining planning environment}

\subsection{Overall collaborative framework}

The fully mechanized three-machine collaborative planning prototype system framework (Shi et al. 2016) is shown in the Fig. 1. Using the theoretical basis provided by the fully mechanized mining process, a dynamic mathematical model is established. A semi-physical simulation compiling the synergistic movement of the three machines has been built on the simulation platform Unity3D in C\# using MAS theory (Xie et al. 2018c)

The system is based on the manual operation of the hydraulic support during the fully mechanized mining process and the three-machine cooperative operation through autonomous linkage of the three machines.

During manual operation, an operator sets the traction speed of the shearer in advance and uses the positional relationship between the front and rear drums and the hydraulic support to push the slide-descending columnmoving frame-column lifting and other operations of the hydraulic support. During automatic operation, an almost constant shifting frequency is maintained; during coordinated-control operation, the shifting frequency of the hydraulic support is updated using the shearer's traction speed and dynamic factor $k_{i}$.

During autonomous linkage operation, the displacement mode of the hydraulic support (sequential moving frames and staggered moving in the group frames) is determined according to the distance between the rear drum and the hydraulic support of the shearer. When the distance between the front drum of shearer and the hydraulic support is two sets of hydraulic support, the hydraulic support retracts a protecting piece of hydraulic support. When the distance between the rear drum of the shearer and the hydraulic support that will perform the action of descending columnmoving frame-uplifting column is less than seven times the hydraulic support distances, sequential moving frames are adopted; i.e., there is only one moving frame. When the coal mining machine is greater than 7 sets, a staggered-movingframe mode of hydraulic support is adopted. During automatic operation, the two staggered hydraulic supports perform the "descending column-moving frame -lifting Column" movement. The moving-frame's frequency is set in advance. Coordinated control movement is established using the position of the shearer and adjusting the dynamic factor $k_{i}$, a mathematical model of the hydraulic support moving-frame frequency based on the shearing speed of the shearer, is established. Therefore, this allows the frequency of the hydraulic support moving frame to be adjusted in real time. As the shearer is followed by the hydraulic support, the comprehensive mining efficiency is improved.

\subsection{Mathematical model of three machine movement in a fully mechanized mining face}

To prevent the shearer drum from cutting the guard plate, the guard plate is recovered adjacent to the hydraulic support in front of the shearer. After the shearer passes the 
hydraulic support on the basis of the scraper conveyor, a "descending-moving-lifting" sequence, shown in Fig. 2, is completed to realize timely support and prepare for the next cut of the shearer. After the hydraulic support has completed the action of the moving frame, the guard plate is stretched to protect the coal wall and prevent it from collapsing.

A mathematical model of the three-machine coordinated movement was created through the cooperative operation of the three machines.According to the position of the shearer, the front hydraulic support retracts the guard plate, and the rear hydraulic support moves in time to realize the support of the suspended ceiling and coal wall after coal cutting. The rear bracket is pushed, the scraper conveyor is controlled, and the fallen coal pieces are loaded onto the scraper conveyor for transport. This allows the automatic migration of coal mining equipment at the working face and ensures that the shearer and hydraulic support do not interfere with each other.

\subsection{Semi-physical simulation construction of fully mechanized mining units in Unity3d}

In this system, the coal-mining machine, scraper conveyor, hydraulic support group, hydraulic liquid supply pump, and down hole working surface are used as agents. And the information interaction and perception with multiple agents (Xie et al. 2017, 2019a) realizes the whole collaboration and achieves efficient coal mining.

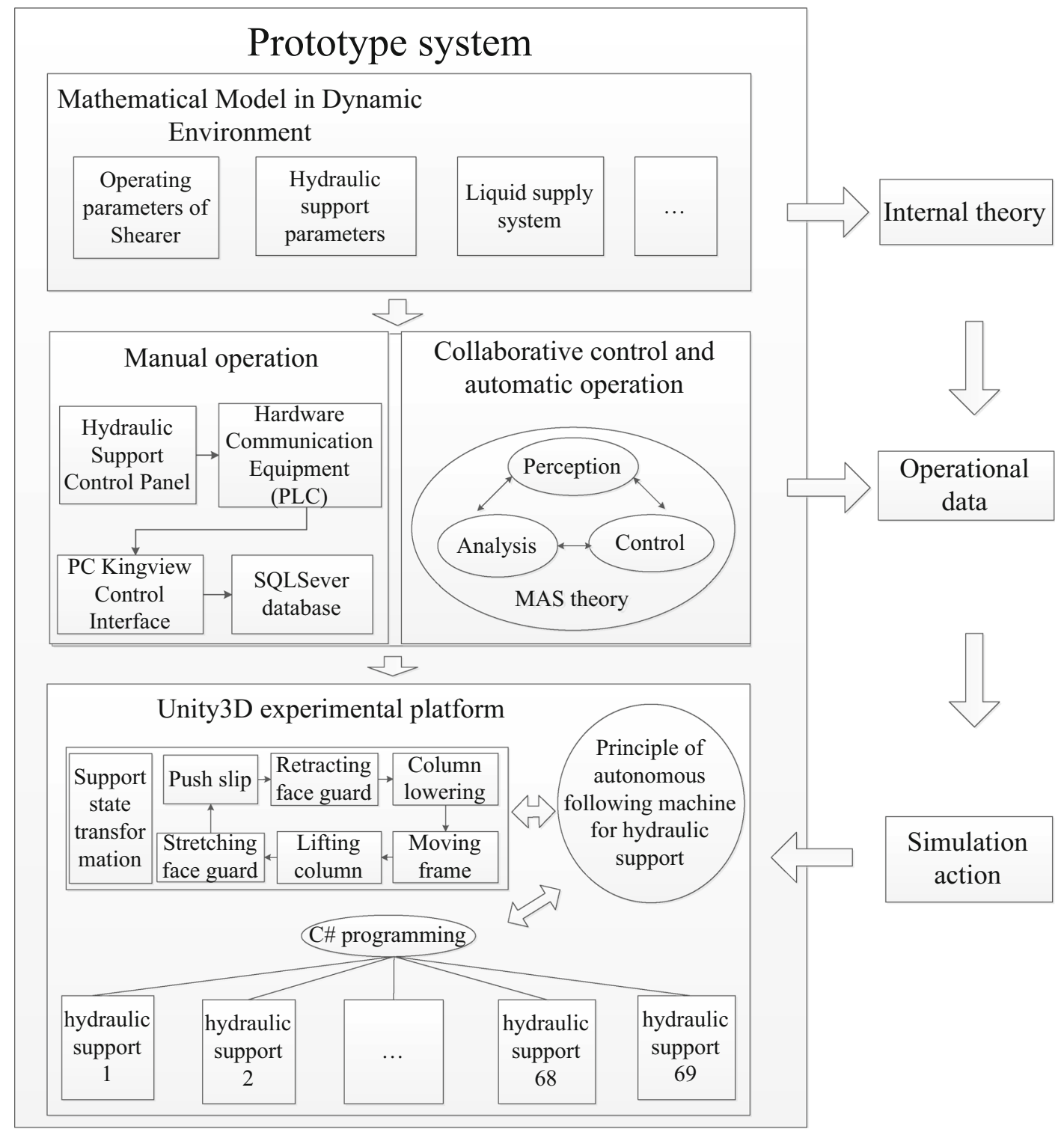

Fig. 1 Overall framework of three machines VR cooperative planning 

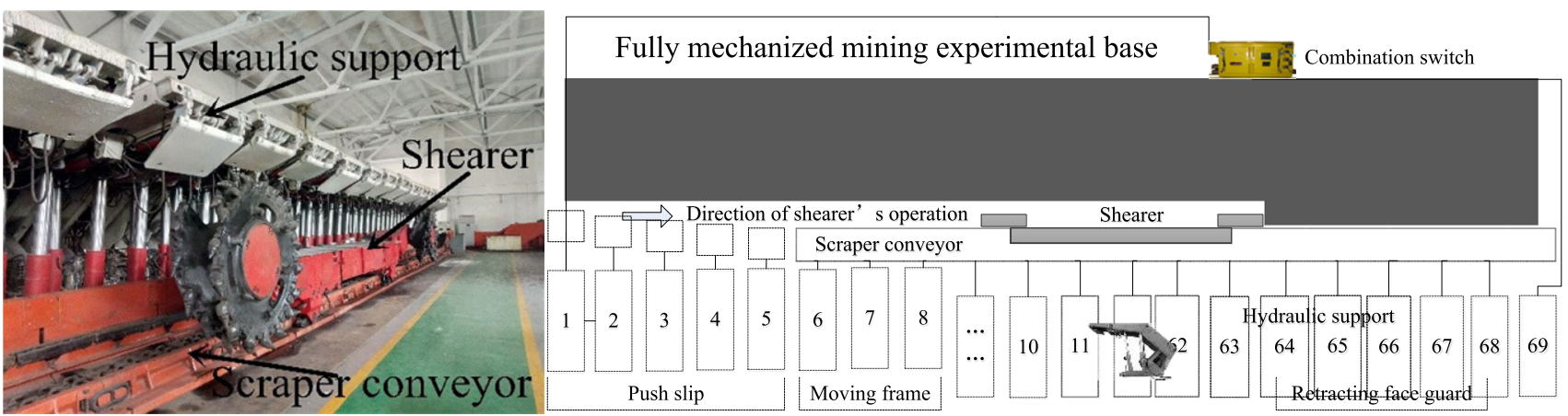

Fig. 2 Collaborative coupling among the structures of three machines in fully mechanized mining

To allow the three machines to interact effectively with each other and the down hole environment, aUnity3D model system framework was built between and is shown in Fig. 3.

(1) Establishing the unity $3 \mathrm{~d}$ simulation model of multiagent, the main goal of multi-agent (Philip Chen et al. 2014) is to make the intent, planning, and action of multiple agents cooperate to complete the operation of the automation system. The system can realize multiple agents to interact in a consistent and harmonious manner. And the purpose of coordination is mainly to avoid an infinite loop between agents.

(2) Its motion is controlled by mounting a C\# script. The part that needs precise control can write a motion command with parameters in the cyclic method to control the parameters to achieve precise control of the motion.

The three machines of the fully mechanized mining face work together to complete the production task to realize the coordinated movement of the three machines. The shearer runs along the trajectory of the scraper conveyor at the traction speed. When the bracket has two brackets away from the front drum of the shearer, the guard plate is retracted. When the hydraulic support is three yards away from the rear of shearer and the movement of the previous bracket has been completed, the hydraulic support is moved at the same time.

\section{Coupling of the hydraulic support automatic flow-up control and shearer speed}

\subsection{Hydraulic support autonomous machine principle}

The coordinated operation (Zhou 2014) of the three machines requires synergy between the shearing speed $V_{q}$ of the shearer and the moving frame speed $V_{y}$ of the hydraulic support. The definition variable num indicates the number of moving of the current hydraulic support. When $n u m=1$, a sequential shifting mode is adopted; when $n u m==2$, the two hydraulic brackets adopt an interlaced moving mode, in which hydraulic support $i$ (the number of the hydraulic support being moved) is synchronized to move with the $i+2$, that is, the support in both moving-ame frequency and moving speed. When the distance to the rear of shearer reaches 7 , the shearer starts to delerate. After the removal of the last hydraulic support, it switches to the staggered moving-frame mode. When the distance between the machine and the machine is less than or equal to 7, the shearer accelerates and switches tohe sequence. The way of moving.

\subsection{Determination of the frequency of the hydraulic support shifting frame $f_{s}$}

The way of moving the frame is determined by the distance between the end of the shearer and the hydraulic support that will perform the action of descending column-moving frame-uplifting column. By adopting different moving rules and adjusting the dynamic factor, the shearer is followed by the hydraulic support. The time variables were defined as: $t_{1}$ is the time of hydraulic support descending column, $t_{2}$ is the time of hydraulic support lifting column, and $t_{3}$ is the time of the stretched of protecting piece of hydraulic support.

According to the distance between the shearer and hydraulic support and the shearing speed, the movingframe frequency of the rear bracket can be determined by the shearing speed of the shearer is $V_{q}$, the relative position of the shearer and the hydraulic support is $i$, and $i$ is the position of the shearer measured by the hydraulic support number. When the distance between the hydraulic support and the rear of the shearer is less than or equal to 7 , one hydraulic support performs the movement action num $=1$. The action frequency can then be calculated as: 


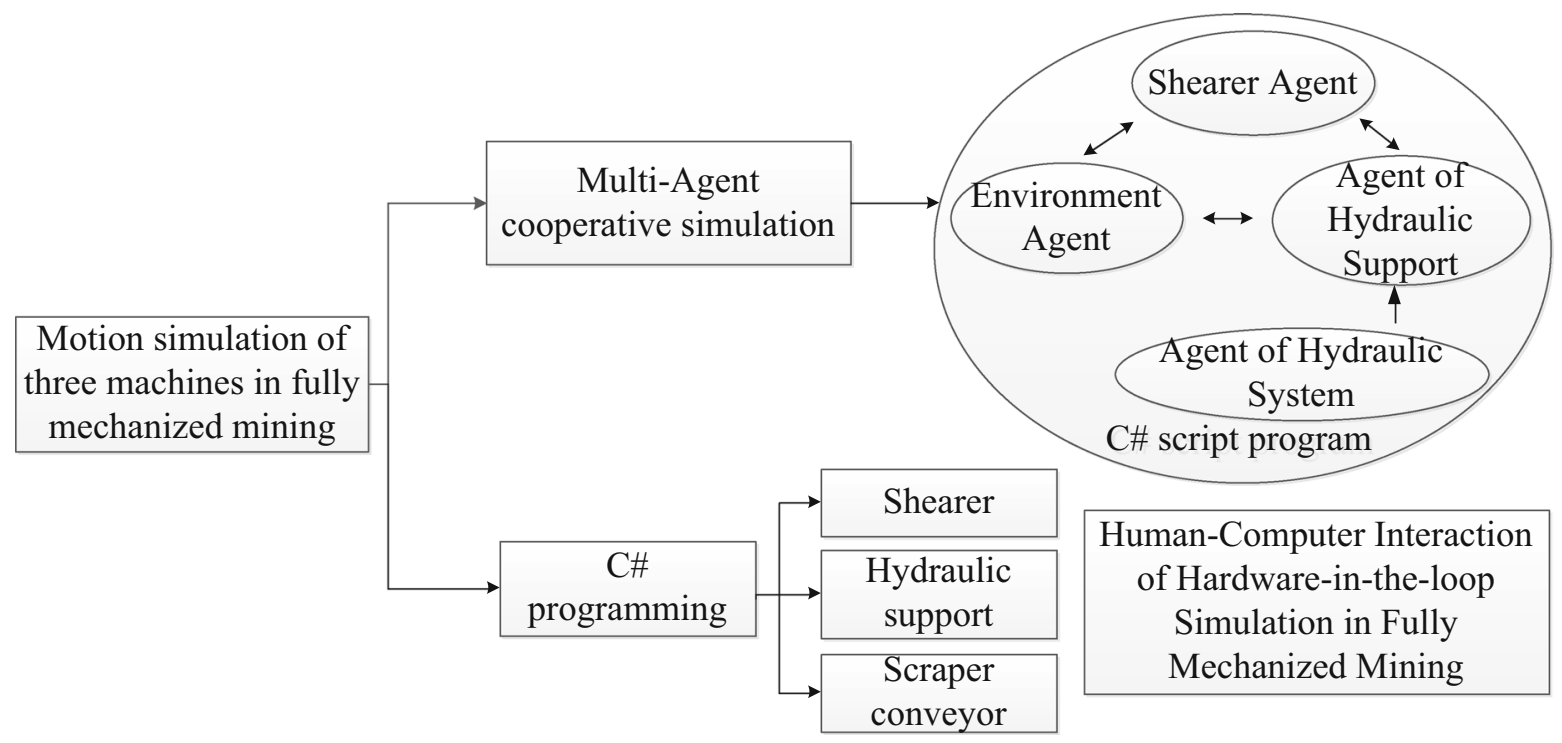

Fig. 3 System framework

$f_{s}=\frac{V_{q}}{\left(d+k_{i} \cdot \Delta d\right)}$

When the distance is greater than 7 , two or three brackets are used simultaneously to perform the corresponding action num $=2,3$. The bracket's action frequency is thus:

$f_{s}=V_{q}^{n u m} \cdot \frac{\left(t_{1}+t_{2}+t_{3}\right)^{(n u m-1)}}{\left(d+k_{i} \cdot \Delta d\right)^{n u m}}$,

Where $\Delta d$ is the average distance between hydraulic supports $(0.7 d m), d$ is the average width of the hydraulic support base $(14.30 \mathrm{dm})$, and $k_{i}$ is the dynamic adjustment factor, with an initial value of 1 , for dynamically adjusting the average calculated distance between adjacent hydraulic supports.

\subsection{Determination of real-time dynamic factor $k_{i}$ based on hydraulic support and other parameters}

\subsubsection{Determination of $k_{i}$}

The shearer was assumed to run in the direction $\vec{D}$ is of +1 . When num $=1$ :

$S_{t}=\left(i_{t}-1\right) \cdot k_{i} \cdot \Delta d+i_{t} \cdot d$,

where $i_{t}$ is the position number of the shearer relative to the hydraulic support, $S_{t}$ is the walking coordinate distance of the shearer along the scraper conveyor, and $i_{t}=\vec{I}(1)$ updates the value of the dynamic adjustment factor $k_{i}$, including:

$k_{i}=\left(S_{t}-i_{t} \cdot d\right) /\left(\left(i_{t}-1\right) \cdot \Delta d\right)$.
When num $\neq 1$, the current $i_{t}$ : is calculated as:

$i_{t}=\operatorname{sum}(\vec{I}) /$ num,

where num is the number of representatives who are moving and $\vec{I}$ is the collection of numbers of relative positions between shearer and hydraulic support. The distance $S_{c}$ of the shearer along the scraper conveyor is then calculated as:

$S_{c}=i_{t} \cdot d+\left(i_{t}-1\right) \cdot k_{i} \cdot \Delta d$,

where $S_{c}$ represents the calculated distance of the shearer along the scraper conveyor (calculated by the number of brackets). The error between the $S_{t}$ and $S_{c}$ : can then be represented as:

$S_{\text {err }}=\left|S_{c}-S_{t}\right|$

If $S_{\text {err }}$ exceeds a certain error range $\varepsilon$, the dynamic adjustment factor $k_{i}$ value is updated as:

$k_{i}=\left(S_{t}-\left(\frac{\operatorname{sum}(\vec{I})}{n u m}\right) \cdot d\right) /\left(\left(\frac{\operatorname{sum}(\vec{I})}{n u m}-1\right) \cdot \Delta d\right)$.

The relative position number of the shearer and the hydraulic support $i_{c}$ is:

$i_{c}=\left(S_{t}+k_{i} \cdot \Delta d\right) /\left(d+k_{i} \cdot \Delta d\right)$

$i_{c}$ is the calculated number of relative position of shearer and hydraulic support. The error between the current $i_{c}$ and $i_{t}:$ is then calculated as:

$i_{\text {err }}=\left|i_{c}-i_{t}\right|$. 
If $i_{\text {err }}$ exceeds a certain threshold range, the dynamic adjustment factor value $k_{i}$ is updated:

$k_{i}=\left(S_{t}-\left(\frac{\operatorname{sum}(\vec{I})}{\text { num }}\right) \cdot d\right) /\left(\left(\frac{\operatorname{sum}(\vec{I})}{\text { num }}-1\right) \cdot \Delta d\right)$

$S_{t}$ is the walking coordinate distance of the shearer along the scraper conveyor. $S_{c}$ represents the calculated distance of the shearer along the scraper conveyor (calculated by the number of brackets). $i_{t}$ is the position number of the shearer relative to the hydraulic support. $i_{c}$ is the calculated number of relative position of shearer and hydraulic support. num is the number of representatives who are moving. $\vec{I}$ is the collection of numbers of relative positions between shearer and hydraulic support. $\vec{D}$ is the collection of coal mining machine running direction, +1 to the left, -1 to the right, and 0 to the static.

\subsubsection{Determination of the speed of the hydraulic support frame $V_{y}$ based on the speed of the shearer}

Shearer traction speed: $V_{q} \mathrm{~m} / \mathrm{min}$

The speed of the hydraulic support frame on the working face: $V_{y} \mathrm{~m} / \mathrm{min}$

$V_{y}>K_{c} \cdot V_{q}$

$K_{c}$ is the unbalance factor; $K_{c}=1.17-1.22$

The average moving speed of the hydraulic support during the shifting process was then calculated using the hydraulic bracket shifting frequency:

$V_{y}=s \times f_{s}$

where $s$ is the distance of the moving frame in $\mathrm{mm}$.

\subsubsection{Calculation of driving power}

A case study was then analyzed using anXR-WS1000 emulsion tank driving aZZ4000/18/38 hydraulic bracket movement. The basic parameters of the emulsion tank were a nominal pressure of $31.5 \mathrm{MPa}$, a nominal capacity of $1000 \mathrm{~L}$, and a nominal flow rate of $125 \mathrm{~L} / \mathrm{min}$. The rod cavity diameter of the ZZ4000/18/38 hydraulic support and of the pushing mechanism were $d=185$ and $d_{1}=85 \mathrm{~mm}$, respectively. The rod-less and rod-free cavity diameters were $D=200$ and $D_{1}=160 \mathrm{~mm}$, respectively. The moving frame of hydraulic support mainly utilizes the flow in the hydraulic cylinder (Zhang 2003):

$Q_{L}=1000 V_{y} \cdot k_{f} \cdot \frac{n_{1} s_{1} F_{1}+n_{2} s_{2} F_{2}+n_{2} s_{2} F_{3}}{d+\Delta d}$,

where $\mathrm{Q}_{\mathrm{L}}$ is the flow volume $(\mathrm{m} / \mathrm{min})$ in the hydraulic cylinder, $V_{y}$ is the speed of the hydraulic support frame, $k_{f}$ is the richness factor of the liquid working conditions, $n_{1}$ is the number of pushing jacks, $s_{1}$ is stepping distance of support moving, $F_{1}$ is the piston action area in pushing jack rack, $n_{2}$ is the number of columns, $s_{2}$ is the height of the lifting and descending column, $F_{2}$ is the piston acting area when falling column, and $F_{3}$ is the piston acting area when lifting column. Based on the case study, $k_{f}$ was assumed to be 2.5 to account for the leakage factor, sputum, and shelf adjustment. Additionally, $s_{1}, F_{1}, n_{2}, s_{2}, F_{2}$, and $F_{3} \mathrm{~m}^{2}$ were assumed as $0.6 \mathrm{~m}, 0.014 \mathrm{~m}^{2}, 4,0.2 \mathrm{~m}, 0.005 \mathrm{~m}^{2}$, and $0.031 \mathrm{~m}^{2}$, respectively. Thus, (12) can be simplified as:

$Q_{L}=1000 V_{y} \times 2.5 \times \frac{\left[0.6 \cdot F_{1}+\left(0.8 F_{2}+0.8 F_{3}\right)\right]}{15 / 10}$

$Q_{L}=62 \times V_{y}$

Under a certain pressure $\Delta p$, the driving power $N$ of the pump varies with the output flow $Q$ as:

$N=\frac{Q_{L} \times \Delta P}{60 \times \eta_{t}}$,

where $\Delta P$-pump represents the difference in pump inlet and outlet pressure in $\mathrm{MPa}$ and $\eta_{t}$-volumetric represents the volumetric pump efficiency, assumed here as 0.85 .

\subsubsection{Determination of output pressure}

As the initial holding force of the hydraulic support and the pushing and pulling force of the pushing jack depend on the working pressure of the pump, it must selected taken the requirements of these two aspects into account. The working pressure of the pumping station was thus selected by taking the maximum value and increasing the pipeline system pressure loss by $10 \%-20 \%$, according to formulas (14) and (15). In the case study examined, the XR-WS1000 emulsion tank drivesaZZ4000/18/38 hydraulic support. The initial support force of the hydraulic bracket is 3520 $\mathrm{KN}$, and the displacement force when the hydraulic bracket is moved is $400 \mathrm{KN}$.

From the initial support force:

$p_{b}=4 \times \frac{F_{1}}{\pi \cdot D^{2} \cdot Z}\left(\mathrm{~N} / \mathrm{m}^{2}\right)$,

where $F_{1}$ is the initial support force of the bracket in $N, Z$ is the number of columns for hydraulic supports, and $D$ is the inner diameter of the cylinder of the bracket column in meters.

According to the maximum thrust of the jack,

$p_{b}=4 \times \frac{F_{n}}{\pi \cdot D_{1}^{2}}\left(\mathrm{~N} / \mathrm{m}^{2}\right)$,

where $F_{\mathrm{n}}$ is the maximum thrust of the jack in $N$ and $D_{1}$ is the inner diameter of the jack cylinder in meters. 


\section{Semi-physical simulation of fully mechanized mining units}

\subsection{Overall hardware-in-the-loop simulation design for hydraulic support of fully mechanized mining inUnity3D}

A semi-physical simulation experimental platform, shown in Fig. 4, was constructed using the semi-physical simulation (Xie et al. 2019a) theory. During operation, a command is issued through the operation panel to the Siemens s7-200PLC and transmitted via Ethernet to the programmable logic controller (PLC) and KingView. The data is transmitted in real-time between the SQLServer database, KingView and unity3d, based on the ideal platform three-machine synergy unity3d constructed by the group (Ramamritham et al. 2004). The hydraulic support is then moved manually.

Siemens s7-200 and industrial configuration software were connected using a Siemens s7-200 Ethernet module following the modbus protocol. An I/O digital signal of the PLC output is sent to the KingView monitoring host, which then uploads the collected data in real time. Through programming in Unity3D to access the SQLServer database, the hydraulic support group is controlled on the virtual platform. The specific technical route is shown in Fig. 5.

\subsection{Siemens PLC command control panel and SQLServer database real-time coupling}

\subsubsection{Instruction panel design}

Moving a single hydraulic support requires a series of actions, including retracting of a protecting piece of hydraulic support, descending the column-moving frame, lifting the column, stretching of protecting piece of hydraulic support, and pushing-sliding. In the Unity3D three-machine comprehensive mining interface, the hydraulic support group is controlled through six command signals, the functions of which are elaborated on in Table 1:

0 push-slip,

1 retracting the protecting hydraulic support piece,

2 lowering the column,

3 moving the frame,

4 ascending the column,

5 stretching the guard plate, and

- 1 releasing the operation of hydraulic support

In addition, there is an ID selection button for selecting the hydraulic support and a button for creating a database.
During manual operation, an SQLServer data table must be created first. Then, the SQLServer data base is opened manually, allowing increments to be written to the SQLServer database script library. Unity3d can then read this written data in the order of ID number.

\subsubsection{Reading and storing the PLC instructions}

The modbus communication protocol embedded in KingView was used to realize the real-time communication between the Siemens PLC and KingView and to establish the corresponding variables in the KingView Data Dictionary. The command code data is stored in the bind record of KingView. The corresponding device data is collected from the signal acquisition and transmission system in real time and transmitted to the database through the ODBC interface. By establishing the ODBC interface, writing the code in the KingView software, writing the connection code, and opening the monitoring interface and setting the insertion frequency, the data is transferred to the database Server in real time.

\subsubsection{Unity3D and SQLServer database coupled three- machine simulation test bench}

Unity3D uses C\# to update events using the function of loop execution and can be executed at fixed time intervals without being affected by the frame rate. By accessing the latest data in the SQLServer for multiple times, real-time access can be achieved. The model performs the action in the simulation at the same time.

Among them, the largest ID row from Table 1 is read and written to indicate the latest row of data in the database to be read. After the data is read, the number of the hydraulic support is determined to be executed, that is, the support ID in the drawing. The function statements of connecting string variables are then used to convert the digital signal of the hydraulic support into a string yyzzdizuozhongnum, e.g., yyzz-dizuozhon69, and is assigned to lampard to determine whether the current hydraulic support ID is consistent with the read ID number. The various actions of the hydraulic support are then performed if the current hydraulic support ID is consistent with the read ID number.

\subsubsection{System design}

The simulated hydraulic support is controlled by a PLC on Unity3D; the overall frame diagram is shown in Fig. 6. The relay control of the PLC is first used to control the button control set on the KingView software. Here, the industrial modbus protocol is used to control KingView. The KingView is controlled byaS7-200 controller. Among them, in 


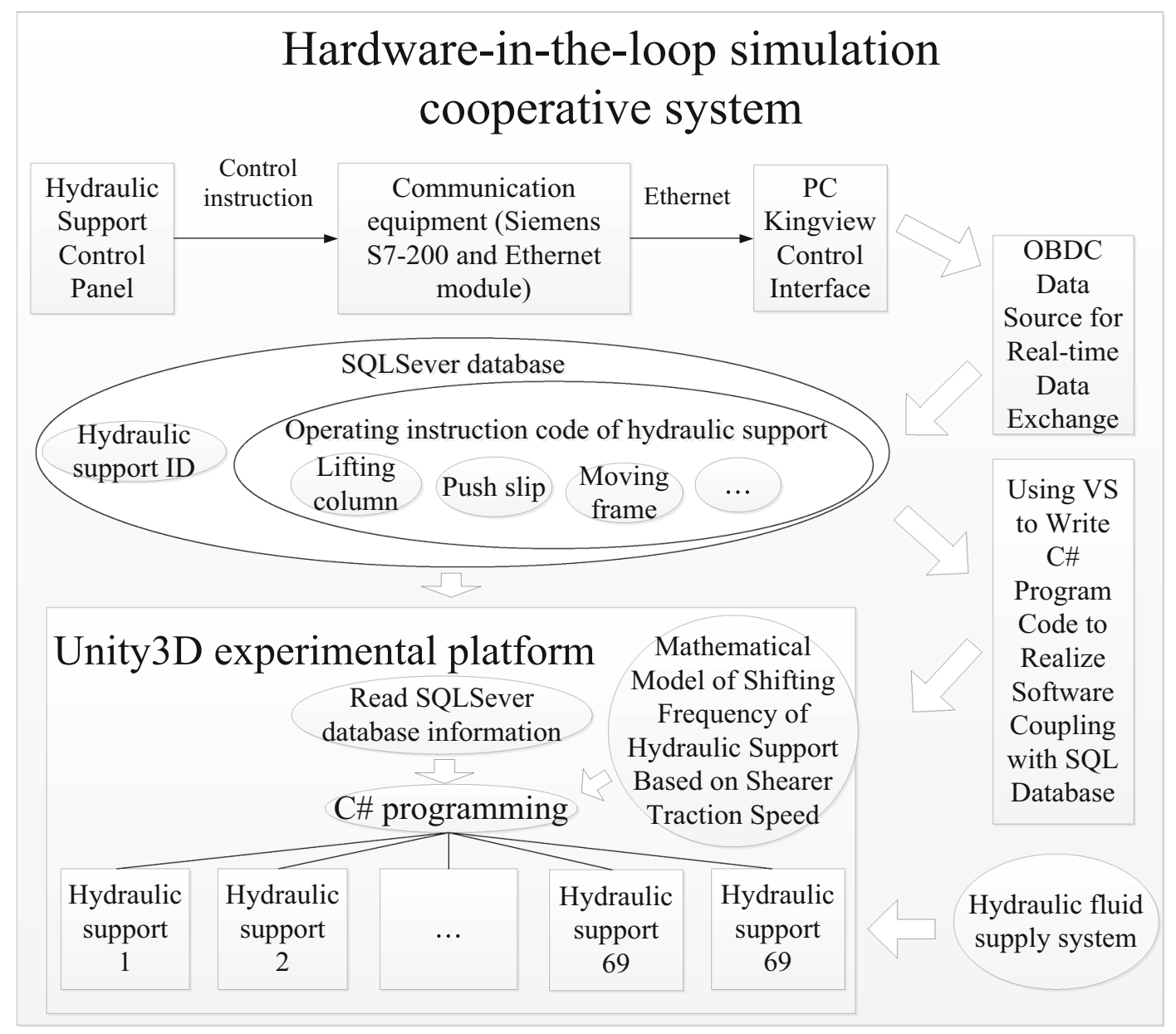

Fig. 4 Hardware-in-the-loop simulation experimental platform

order to realize the communication between the PLC controller and the KingView, it is necessary to give the PLC controller program control code.

The PLC signal collected by KingView is then saved to the SQLServer by writing code program in the KingView (the number ID and operation instruction of hydraulic bracket).The real-time interactive corresponding program between KingView and SQLServer database is written in the KingView's command language window.

Unity3D then reads the data to realize the dynamic control of the hydraulic support in real time by writing C\# program in the script (as is shown in Fig. 7).Among them, the block diagram of the hydraulic support operation script program is shown in Fig. 8.

The data is then used to debug and define the integer variable. By writing the increment of the integer variable to record the running time of the program through the function of loop execution, the specified statement is written when the hydraulic support moves for recording the time. The outputting shearer position is then written when the hydraulic support moves for recording the real-time position of the shearer. Find the value of Edit $->$ Project Settings $->$ Time $->$ Fixed Timestep in Unity3D (for example: 0.2, which means one frame per $0.2 \mathrm{~s}$ ), the instantaneous running speed of the shearer, based on the amount of change in the integer variable and the amount of change in the real-time position of the shearer, can be acquired by using interpolation calculation. Meanwhile, the time required for the moving of the moving frame is measured. Its reciprocal is then used find the frequency of the moving frame.

The group of the hydraulic support is controlled by the PLC in Unity3d. The detected program needs to be released into the $\mathrm{PC}$ version that can avoid causing the computer to collapse. 


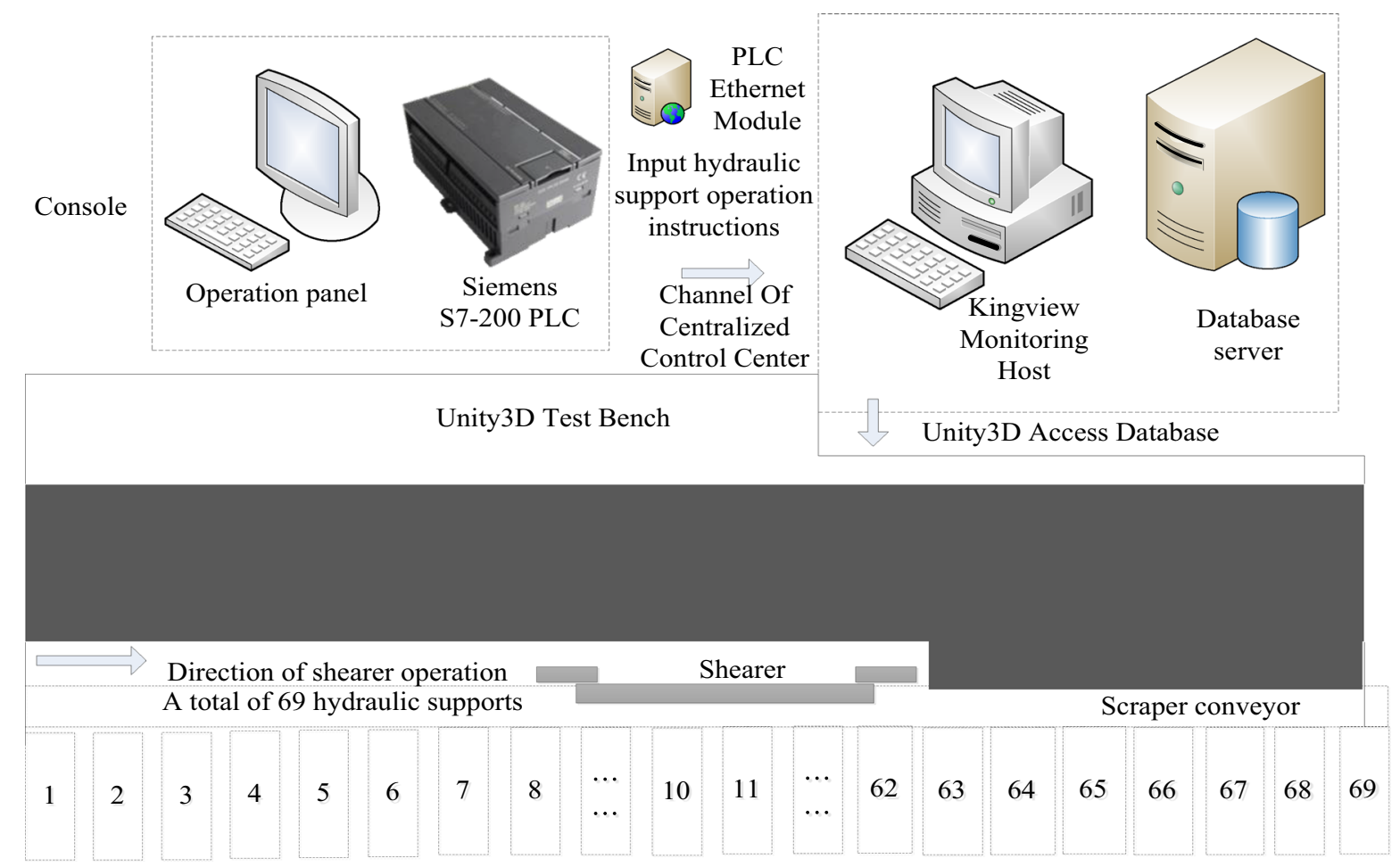

Fig. 5 Overall design of three machines real-time simulation for fully mechanized mining

Table 1 Operating instructions for hydraulic support control panel

\begin{tabular}{llll}
\hline $\begin{array}{l}\text { Serial } \\
\text { number }\end{array}$ & $\begin{array}{l}\text { PLC input } \\
\text { button }\end{array}$ & $\begin{array}{l}\text { Kingview reads and stores in SQL SEVER database } \\
\text { (digital code) }\end{array}$ & Unity3D hydraulic support (1-69 sets) \\
\hline 1 & I0.0 & -1 & Remove the control of the hydraulic support \\
2 & I0.1 & 0 & Push slip \\
3 & I0.2 & 1 & Shrinking time of the side wall plate \\
4 & I0.3 & 2 & Descending column \\
5 & I0.4 & 3 & Moving frame \\
6 & I0.5 & 4 & Lifting column \\
7 & I0.6 & 5 & Stretching of the side wall plate \\
8 & I0.7 & Support ID increase (Kingview memory variable) & Increased ID of hydraulic support \\
9 & I1.0 & Scaffold ID reduction (Kingview memory variable) & Hydraulic support ID reduction \\
\hline
\end{tabular}

\section{Experimental design}

\subsection{Three-machine experimental environment}

An intelligent comprehensive transformation test system of coal mine fully purchased by the laboratory was equipped with a centralized control-monitoring system, so that the comprehensive mining equipment has the actual kinematics ability to realize remote automatic coal mining. An MGTY250/600 shearer and 69 ZZ4000/18/38 hydraulic supports were used, corresponding to a considerable number of SGZ764/603 scraper conveyor, transporter, crusher and combination switch. An XR-WS1000 emulsified tank was used to drive hydraulic support. The device model is shown in Table 2 below, and the overall scenario is shown in Fig. 9.The functions of the fully mechanized mining system included:

(1) a mining machine that can monitor the operation dynamics of the shearer;

(2) a hydraulic support that can be automatically followed by the setting program;

(3) a centralized control platform; 


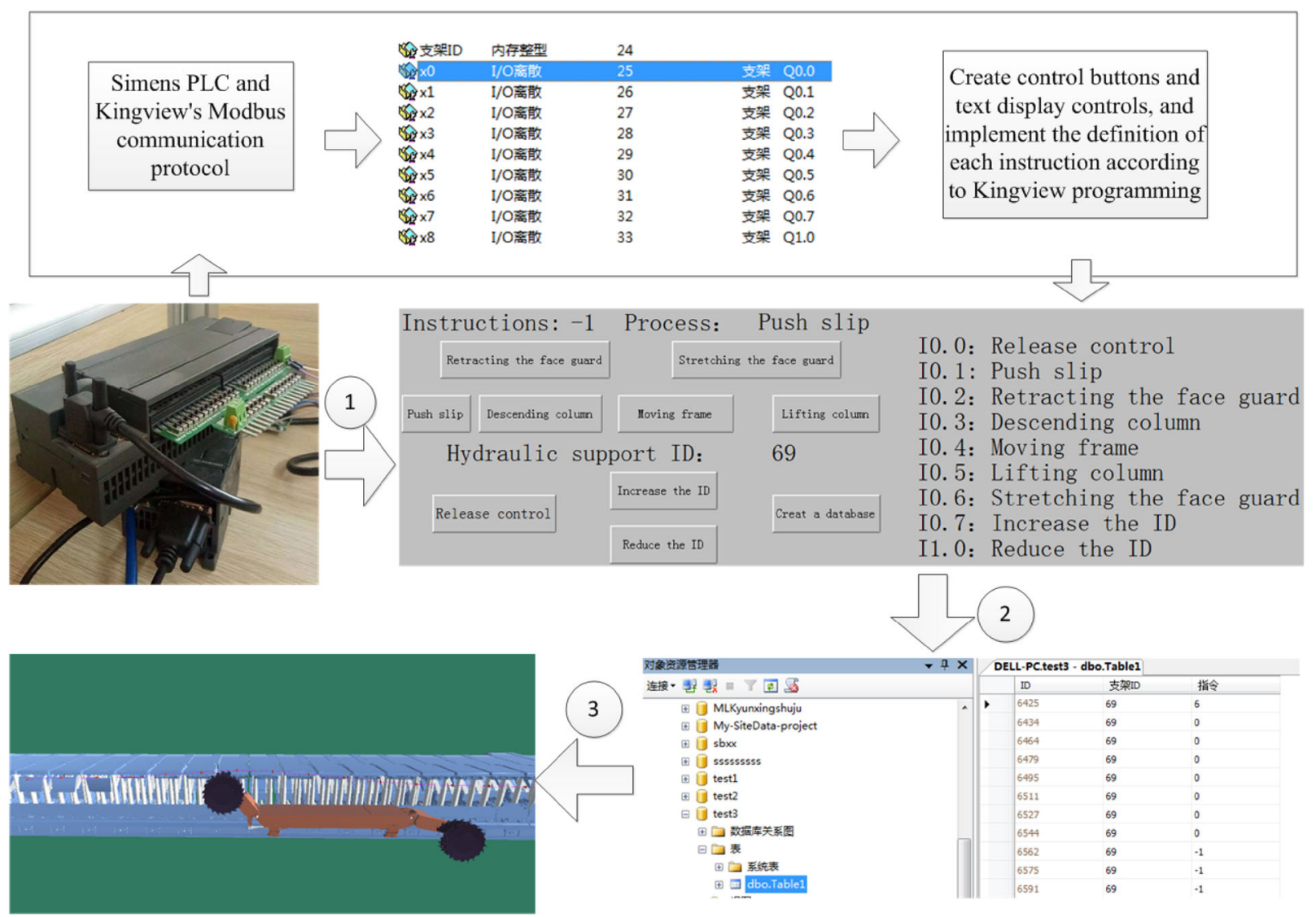

Fig. 6 Overall system framework

Table 2 Specifications of fully mechanized mining test equipment in coal mines

\begin{tabular}{lll}
\hline Serial number & Device name & Model \\
\hline 1 & Hydraulic support & ZZ4000/18/38 \\
2 & Shearer & MGTY250/600 \\
3 & Scraper conveyor pan & SGZ764/603 \\
4 & Stage loader conveyor & SZZ764/164 \\
5 & Crusher & PCM110 \\
6 & Combination switch & QJZ2*400/1140 \\
\hline
\end{tabular}

(4) wireless video surveillance of the mining face;and data monitoring, control, and real-time status display of each piece of equipment during operation.

\subsection{Acquisition of experimental data}

The shearing speed of the shearer was first set by the professional. Two experiments are carried out in the ground laboratory and the Unity3D simulation platform:

(1) The laboratory automatic running program is started in automatic operation mode;

(2) The coal mining machine and centralized control platform are used to control the various actions of the hydraulic support to complete the fully mechanized mining process;

(3) The Unity3Dprogram is started;

(4) The Unity3Dmanual operation mode is started, and the same professional operates the hydraulic support

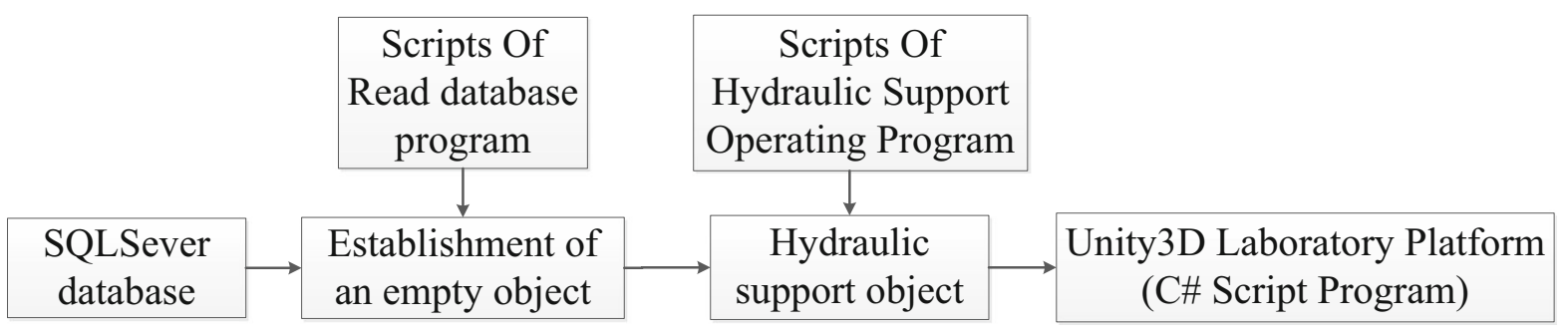

Fig. 7 Real-time interactive flow chart 


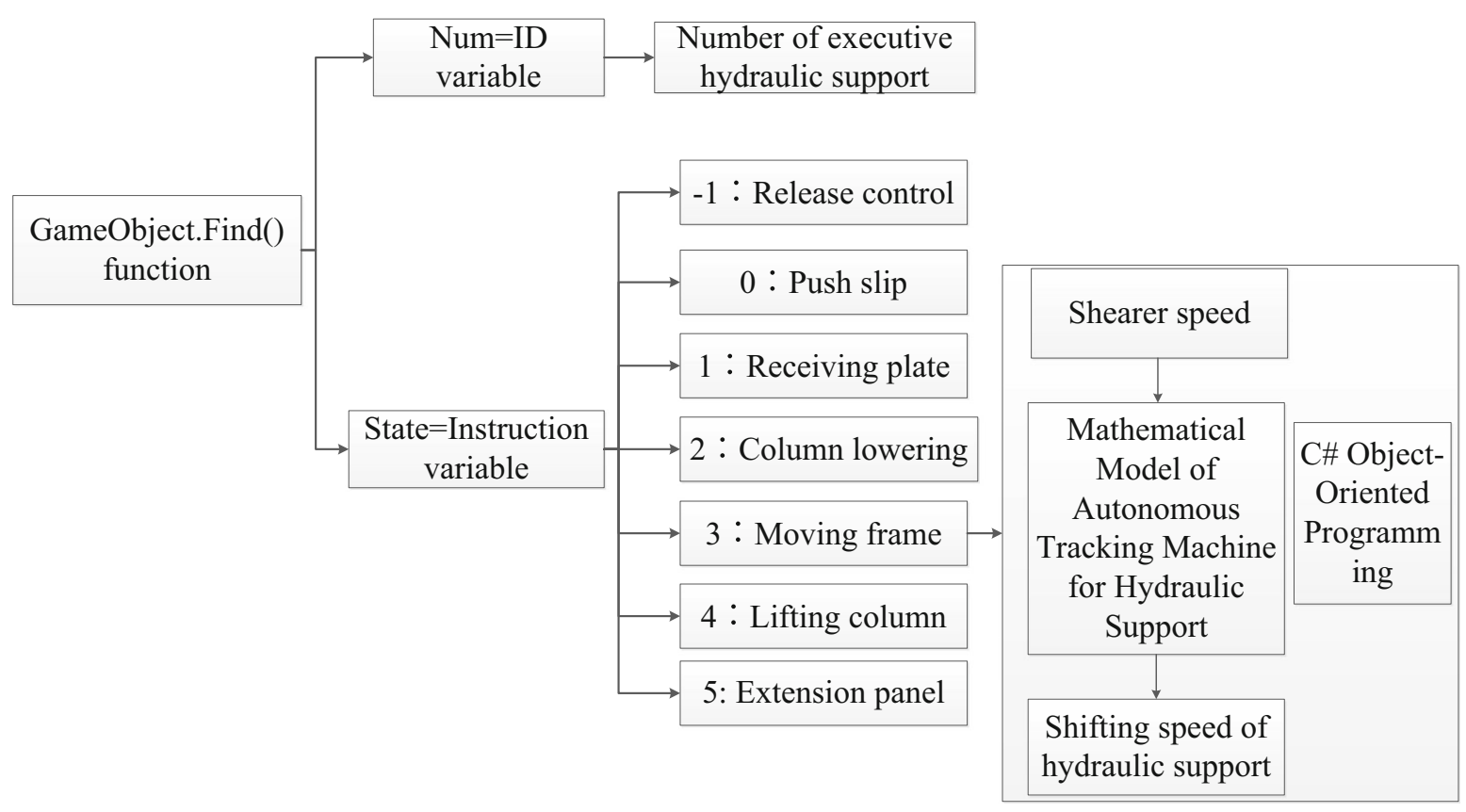

Fig. 8 Drawing of script program for hydraulic support

to complete the operation of the fully mechanized mining.

During the operation of fully mechanized mining equipment, the operation process is shown on the left of Fig. 9. The shearer runs from left to right:

(1) Using the centralized control center (shown in Fig. 9) and hydraulic support number as the abscissa coordinate, the shearer's running speed was recorded in $\mathrm{m} / \mathrm{min}$ when running for more than $5 \mathrm{~s}$. The speed change of the shearer was obtained.

(2) As the first hydraulic support moves, the time $t$ of each hydraulic support move is recorded. The shifting frequencies of all hydraulic supports numbered $1-55$ are calculated as $1 / t$.

(3) As the hydraulic support is moved, in four groups of experiments, the hydraulic supply pressure of the hydraulic support system numbered 1-55 was monitored and measured by the configuration industrial software. The characteristic values were recorded.

Through the statistical comparison of the data as shown in Table 3, the data errors of shearer running speed, hydraulic support moving frequency, hydraulic supply force of hydraulic system and real fully mechanized mining equipment obtained by automatic operation and manual operation of Unity3D simulation experimental platform were within the allowable range. The error ratio, referring to the maximum error in the process of fully mechanized mining between simulation and real experiment was then obtained.
Among them, the shearer's speed is expressed by recording the real shearer's running speed and the simulation experiment shearer's running speed value. After obtaining the shearer's running speed curve, the error ratio of shearer's running speed at each time is calculated. Its maximum value is obtained. Similarly, the hydraulic pressure of the hydraulic system is recorded when the frame is moved. The hydraulic pressure curve of 69 hydraulic supports is drawn. The maximum pressure error is obtained as shown in Table 3. Finally, the maximum error ratio of the shift frequency is obtained by the same method.

The maximum error was within the allowable range. Thus, the developed simulation successfully identified the optimization mode of the fully mechanized mining technology.

\subsection{Experimental design of shifting frequency}

With running the pc end program, the coal mining machine starts running. As the left drum of the shearer rose, the right drum descended and the shearer began to pull toward the tail of the machine. When the shearer is operated to activate the hydraulic support $i$ that is in the corresponding position, the hydraulic support adopted a corresponding moving frame manner, thus allowing the hydraulic support to catch up with the shearer. The distance of the shearer and the hydraulic support will be safe. 


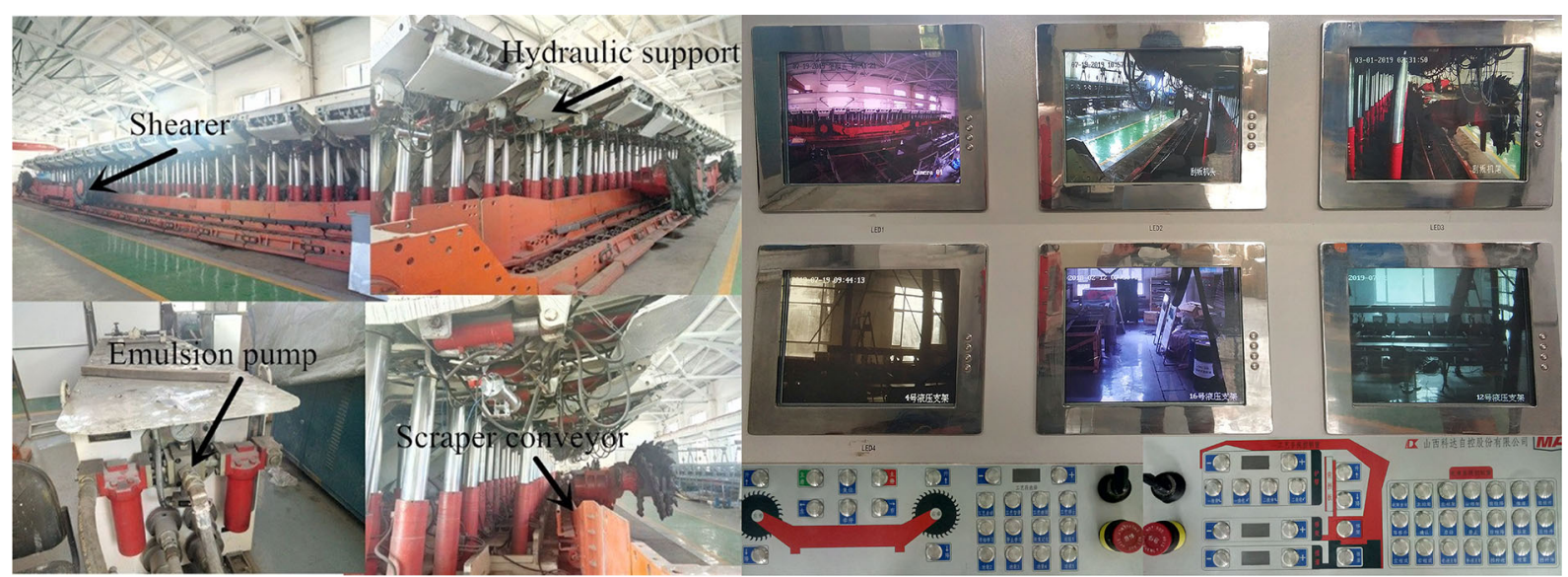

Fig. 9 Three machines experimental platform for fully mechanized mining

The measurement of virtual simulation parameter:

(1) The position of the shearer (global position coordinates and the position numbered by the hydraulic support): is to locate the operating position of the shearer during the operation;

(2) The speed of the shearer: the traction speed of the shearer is measured during the operation process;

(3) Moving-frame frequency: the moving-frame frequency of each hydraulic support can be calculated by recording the moving time of each hydraulic support during the process of moving the hydraulic support.

(4) Supply pressure: Record the supply pressure value provided by the emulsion pump to each hydraulic support during moving-frame process of the hydraulic support.
The data of the simulation process was then processed and extracted by experiments, as shown in Fig. 10. Here, the shearer speed of the three simulation experiments was nearly constant. As the hydraulic support group moved, the shearer's position and traction speed were consistent in the three groups of experiments. It can avoid errors of the research's process of the hydraulic support moving in the three simulation experiments due to the different shearer's traction speed.

The virtual 3D scene rendered the roof and floor curves in real time. Each crucial point is indicated by a small round dot, providing a clear representation of the underground environment. The resulting the time parameters of the corresponding action of the hydraulic support are shown in Table 4.

The distance of the moving frame in the simulation is $600 \mathrm{~mm}$. The broken line diagram of moving-frame

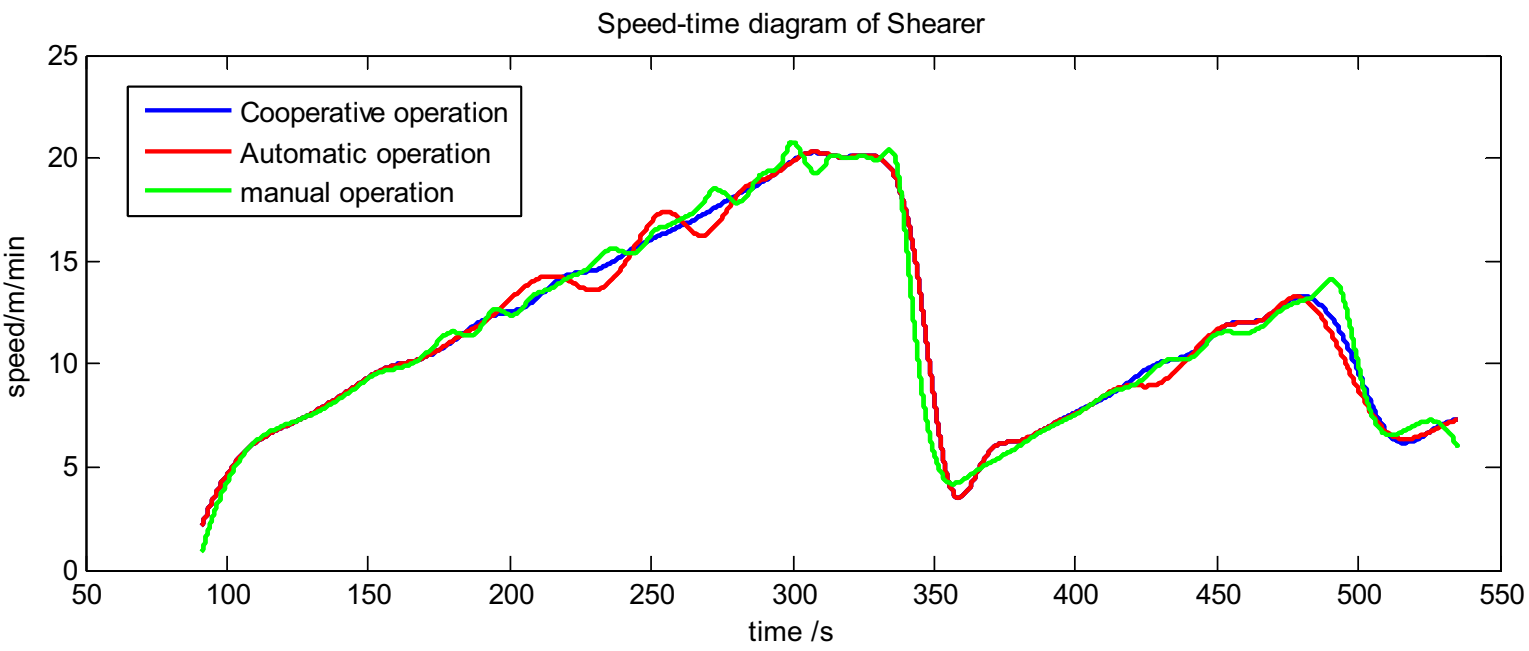

Fig. 10 The running speed of the shearer during the cooperative operation and manual operation 
Table 3 Error ratio of simulation and real data

\begin{tabular}{llll}
\hline Parameter & Shearer running speed $(\mathrm{m} / \mathrm{min})$ & Hydraulic system supply pressure $(\mathrm{MPa})$ & Shift frequency $(\mathrm{Hz})$ \\
\hline $\begin{array}{l}\text { Error ratio (\%) } \\
\text { (Manual operation) }\end{array}$ & 5.42 & 6.89 & 6.52 \\
$\begin{array}{l}\text { Error ratio (\%) } \\
\text { (automatic running) }\end{array}$ & 5.53 & 7.86 & 10.83 \\
\hline
\end{tabular}

Table 4 Operational parameter table of hydraulic support

\begin{tabular}{|c|c|c|c|c|}
\hline Column drop distance (mm) & Column drop time $(\mathrm{s})$ & Column lift time (s) & Stretching time of the side wall plate (s) & Total (s) \\
\hline 200 & 0.88 & 5.97 & 3.8 & 10.65 \\
\hline
\end{tabular}

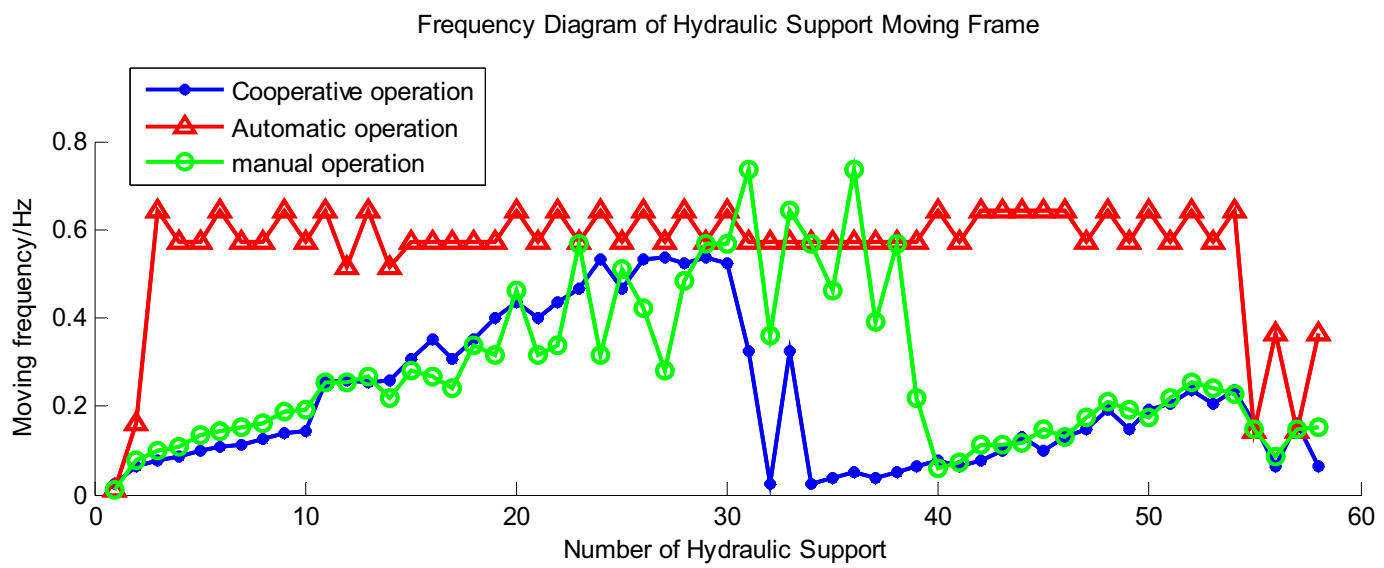

Fig. 11 Frequency comparison of hydraulic support moving in three modes

frequency of the hydraulic support under manual operation, automatic operation (not using the model) and the cooperative control mode is as follows in Fig. 11.

\subsection{Liquid supply experiment}

For the XR-WS1000 emulsion tank driving anZZ4000/18/ 38 hydraulic support, the output flow and driving power of each hydraulic bracket were calculated as:

$Q_{L}=1000 V_{y} \cdot k_{f} \cdot \frac{n_{1} s_{1} F_{1}+n_{2} s_{2} F_{2}+n_{2} s_{2} F_{3}}{d+\Delta d}$

From the reference manual for the emulsion pump, the working and nominal pressure were $P_{1}=30.0$ and $P_{2}=$ $31.5 \mathrm{MPa}$, respectively. Under a certain pressure $p$, the driving power $N$ of the pump changed with the change of the output flow rate $Q$ :

$N=\frac{Q_{L} \times P}{60 \times \eta_{t}}$,

where $P$ is the output pressure of the pump in $\mathrm{MPa}$ and $\eta_{t}$ is the total efficiency of the pump, assumed as 0.85 .
The resulting supply pressure and power loss of the hydraulic support system in the three modes studied are shown in Figs. 12 and 13.

Respectively, the results of the simulation running are calculated and their work efficiency is compared in Table 5. Overall, the synergistic control of the fully mechanized mining efficiency was increased by $3.76 \%$ after the introduction of the dynamic factor. The mining efficiency improved nearly $46.03 \%$ when operation was used, when compared with manual operation. Therefore, the proposed model was deemed to improve overall mining efficiency.

\subsection{Summary and discussion of experiments}

Through qualitative analysis, three fully mechanized mining machines were analyzed under similar conditions. Based on the shearer's traction speed, the frequency of the hydraulic support's moving frame was calculated by continuous circulation to realize timely follow-up of the hydraulic support. To realize effective coordinated 


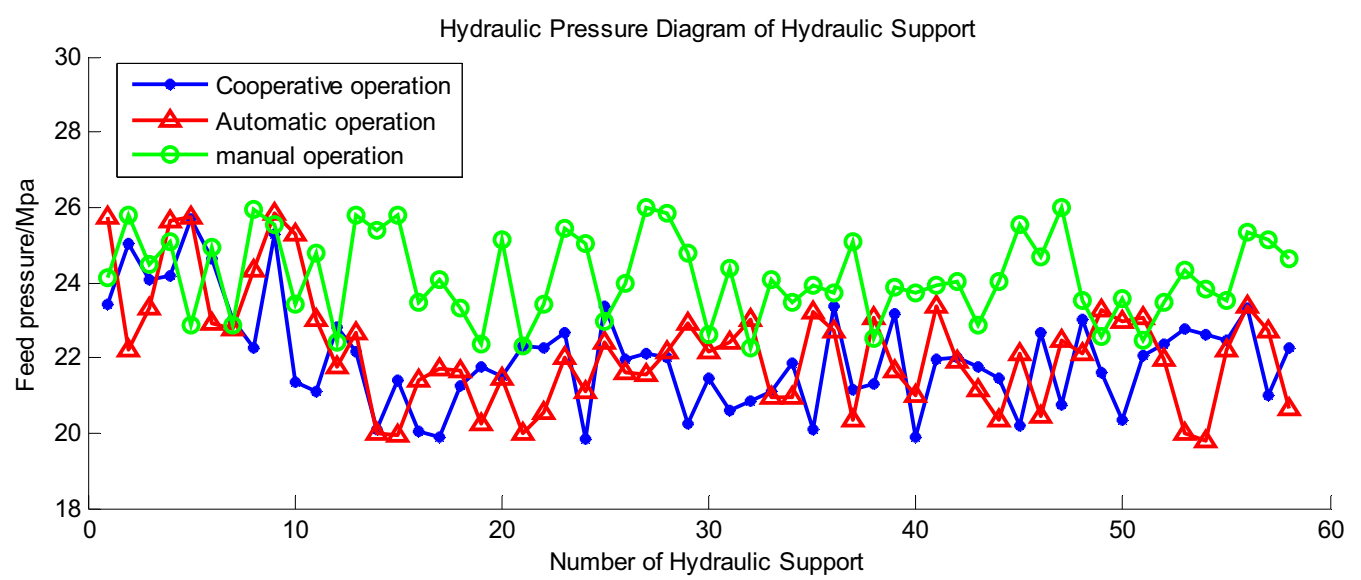

Fig. 12 Hydraulic force diagram

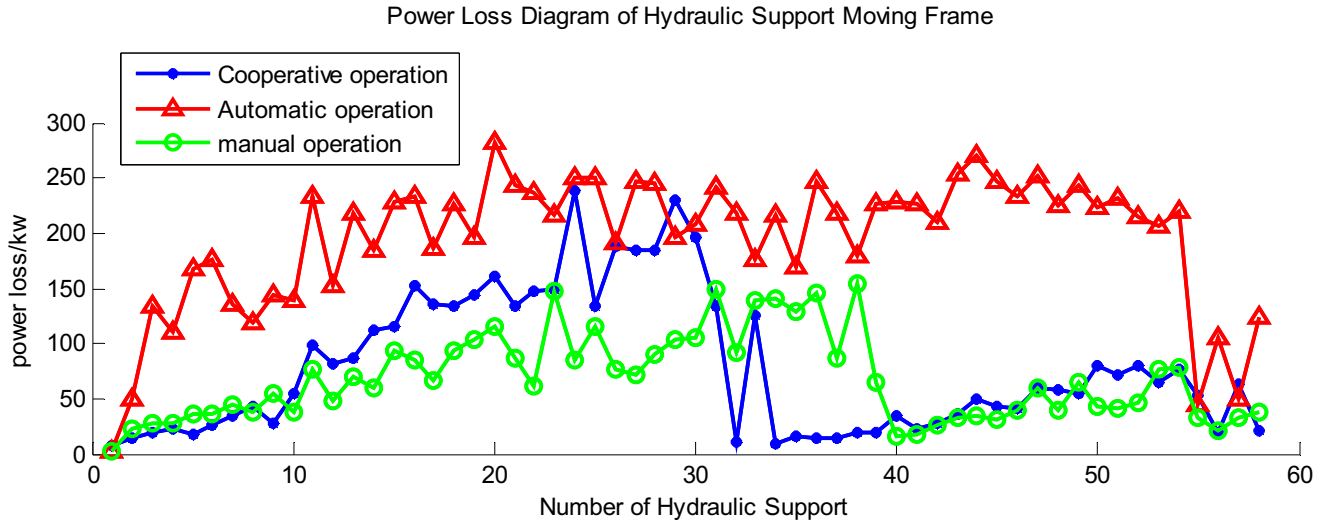

Fig. 13 Power loss diagram of each hydraulic support

Table 5 Comparison of experimental results

\begin{tabular}{lllll}
\hline Mode & $\begin{array}{l}\text { Traction speed }(\mathrm{m} / \\
\mathrm{min})\end{array}$ & $\begin{array}{l}\text { Liquid supply energy } \\
(\mathrm{kw})\end{array}$ & $\begin{array}{l}\text { Production/energy ratio }\left(\mathrm{m}^{3} /\right. \\
\mathrm{kw})\end{array}$ & $\begin{array}{l}\text { Efficiency improvement } \\
(\%)\end{array}$ \\
\hline Manual operation automatic & 13.177 & 36.844 & 0.189 & 146.03 \\
$\quad$ running & 11.357 & 27.373 & 0.266 & 103.76 \\
Collaborative control & 11.357 & 127.538 & 0.276 & \\
\hline
\end{tabular}

movement of the three fully mechanized mining machines, the shearer and hydraulic speed were linked: as the shearer's speed increased, so did that of hydraulic support, and vice versa.

By compiling the mathematical model of the hydraulic support with self-regulating speed into a C\# program, and using object-oriented programming of Unity $3 \mathrm{D}$, the program script is mounted on the corresponding hydraulic support to realize the coordinated control of the system. Finally, the data of the experimental process are recorded by debugging statements, including the shearer's running speed, the hydraulic support's feeding force and the shifting frequency of 69 hydraulic supports. Finally, the working efficiency of the cooperative control operation is calculated.

Similarly, the working efficiency of fully mechanized mining was calculated under manual and automatic operation. Finally, three kinds of hydraulic support were compared with the machine.

The proposed mathematical model was validated on the Unity3Dsimulation platform on the ground. The system has not yet been applied to an underground fully mechanized mining face and thus will be the focus of future work. 


\section{Conclusion}

(1) Through the establishment of simulation model, three groups of experiments were carried out. Frequency measurements of a hydraulic support moving frame were realized using debugging statements in Unity3D. Through calculation and inspection, under the same mining technology conditions, keeping the same mining efficiency of the shearer, the working efficiency of the cooperative control of the hydraulic support is improved by $3.76 \%$ compared with the automatic operation and $46.3 \%$ compared with the manual operation. Thus, the mathematical model of the independent following machine effectively improved the mining efficiency of the fully mechanized mining technology, and provides a theoretical basis for realizing the intelligent operation of the "three machines" in fully mechanized mining.

(2) A hardware-in-the-loop simulation of real-time autonomous tracking of hydraulic support was constructed using real-time coupling technology of PLC, KingView, SQLServer and Unity3D software and hardware data. By using the semi-physical simulation technology of fully mechanized mining, the difficult problem of studying the efficiency of fully mechanized mining technology in underground is solved, and the evaluation and prediction of the follow-up strategy of hydraulic support for fully mechanized mining technology in underground can be realized.

(3) Through experiments in laboratory and unity3D simulation platform, the parameters data of shearer and hydraulic support are recorded, and it is concluded that the simulation experimental platform can be used for experimental analysis of three fully mechanized mining machines. Firstly, simulating the laboratory fully mechanized mining environment on the simulation platform, all hydraulic supports are on the horizontal ground. Secondly, through qualitative analysis, it ensures that the shearer is in the same working condition. That is to say, three sets of simulation experiments of fully mechanized mining keep the same shearer running speed. Finally, manual operation, automatic operation and cooperative control are adopted for three kinds of hydraulic support follow-up modes. The efficiency of fully mechanized mining in the whole process of fully mechanized mining is analyzed.

Acknowledgements This work was supported by the Project funded by China Postdoctoral Science Foundation under Grant 2019M651081, the Merit Funding for the Returned Overseas Personnel Sci-Tech Activities of Shanxi Province under Grant 2016 and Key Research and Development Program of Shanxi (2019) and Innovation Programs of Higher Education Institutions in Shanxi (2019L0305).
Open Access This article is distributed under the terms of the Creative Commons Attribution 4.0 International License (http://crea tivecommons.org/licenses/by/4.0/), which permits unrestricted use, distribution, and reproduction in any medium, provided you give appropriate credit to the original author(s) and the source, provide a link to the Creative Commons license, and indicate if changes were made.

\section{References}

Bednarz T, James C, Widzyk-Capehart E et al (2015) Distributed collaborative immersive virtual reality framework for the mining industry. Mach Vis Mechatr Pract Springer, Berlin, Germany, pp 39-40. https://doi.org/10.1007/978-3-662-45514-2_4

Chen H, Lu M, Wen M, Lv M, Pan Y, Fu X et al (2011) Study on mining technology in intelligent workface of Wannian Colliery. Intell Syst 3:271-274

Dobrescu R, Merezeanu D, Mocanu S (2019) Process simulation platform for virtual manufacturing systems evaluation. Comput Ind 104:131-140

Fan QG, Wu Y, Yu Z (2015) Task coordination control modeling for coal machinery based on generalized partial global planning. J Comput Inform Syst 11(2):501-513

Guo W, Li J (2014) Bracket electro-hydraulic control system based on PLC hydraulic research. Adv Mater Res 1049:1042-1047

Küblera K, Schwarza E, Verla A (2018) Test case generation for production systems with model-implemented faultinjection consideration. In: 12th CIRP conf. intell. comput. manuf. eng., Gulf of Naples, Italy, 18 Jul., vol 79, pp 268-273

Li A, Zheng X, Wang W (2015) Motion simulation of hydraulic support based on unity3D. In: 1st Int. conf. inform. sci., mach., mater. and energy, Atlantis Press, July

Ma HW, Zhang XH et al (2014) Shearer remote control system and remote control method based on virtual reality technology. C.N. Patent 201310468301.2, Jan. 1

Pedram S, Perez P, Dowsett B (2013) Assessing the impact of virtual reality-based training on health and safety issues in the mining industry. In: Proc. conf.: ISNGI2013-int. symp. next generation infrastructure, Wollongong, Australia, October

Perez P, Pedram S, Dowcet B (2013) Impact of virtual training on safety and productivity in the mining industry. In: Conference: MODSIM International symposium for next generation infrastructure, Adelaide, Australia, December

Philip Chen CL, Wen GX, Liu YJ, Wang FY (2014) Adaptive consensus control for a class of nonlinear multi-agent time-delay systems using neural networks. IEEE Trans Neural Netw Learn 25(6):1217-1226

Ralston JC, Hargrave CO, Dunn MT (2017a) Longwall automation: trends, challenges and opportunities. Int $\mathrm{J}$ Min Sci Technol 27(5):733-739

Ralston JC, Reid DC, Dunn MT et al (2017b) Longwall automation: delivering enabling technology to achieve safer and more productive underground mining. Int $\mathrm{J}$ Min Sci Technol 25(6):865-876

Ramamritham K, Sang HS, Dipippo LC (2004) Real-time databases and data services. Real Time Syst 28:179-215

Scheifele C, Verl A, Riedel O (2018) Real-time co-simulation for the virtual commissioning of production systems. In: 12th CIRP conf. intell. comput. manuf. eng., Gulf of Naple, Italys, 18 Jul., vol 79, pp 397-402

Shi Y, Sun Y, Zhong Q, Zhu H (2016) Research on three-dimensional reproduction technology of coal face. In: 2016 International conference on multimedia systems and signal processing 
(ICMSSP), Taipei, pp 105-109. https://doi.org/10.1109/icmssp. 2016.031

Tichon J, Burgesslimerick R (2011) A review of Virtual Reality as a medium for safety related training in Mining. J Health Saf Res Pract 3(1):33-40

Wan L, Gao L, Liu Z, Wang L (2013) The application of virtual reality technology in mechanized mining face. Adv Intell Syst Comput 181:1055-1061

Wang Z, Ni W, Li S, Xu Z (2009) Research on key technologies of remote monitoring platform for shearer. Measuring Tech Mech Autom 1:316-319

Wang Z, Zhou X, Zhao Y, Ji R (2013) Research on real-time driving method of shearer's remote monitoring platform. In: Proc. 2nd int. conf. comput. sci. elec. eng. https://doi.org/10.2991/iccsee. 2013.274

Xie J et al (2017) A joint positioning and attitude solving method for shearer and scraper conveyor under complex conditions. Math Probl Eng. https://doi.org/10.1155/2017/3793412

Xie J, Yang Z, Wang X et al (2018a) A remote VR operation system for a fully mechanised coal-mining face using real-time data and collaborative network technology. Min Technol Trans Inst Min Metall 127(4):230-240

Xie J, Yang Z, Wang X et al (2018b) A virtual reality collaborative planning simulator and its method for three machines in a fully mechanized coal mining face. Arab J Sci Eng 43(9):4835-4854

Xie J et al (2018c) Research on key technologies of virtual collaboration of three machines in fully mechanized coal mining face. Chin J Eng 25(1):90-91

Xie $\mathrm{J}$ et al (2019a) Attitude-aware method for hydraulic support groups in a virtual reality environment. P I Mech Eng C-J Mec. https://doi.org/10.1177/0954406219838574

Xie J, Yang Z, Wang X, Hao S (2019b) Virtual monitoring method for hydraulic supports based on digital twin theory. Min Technol Trans Inst Min Metall 2(128):77-87

Xu ZP, Zhang K, Ji R (2013) Design of electric-hydraulic control system for hydraulic powered support in fully mechanized mining face. Adv Mater Res 753-755:2641-2644
Zhang RL (2003) Manual of mining engineering design, vol 2. China Coal Industry Publishing House, pp 495-572

Zhang S (2011) Augmented reality on long-wall face for unmanned mining. Appl Mech Mater 40-41:388-391

Zhang XH, Du Y et al (2016) Remote training virtual training system for coal mine fully mechanized mining face. C.N. Patent 201510996174.2, Mar. 16

Zhang YK, Xiao LJ (2012) Research on design and simulation of four-bar linkage mechanism of hydraulic support based on virtual prototype technology. Appl Mech Mater 170-173:3539-3542

Zhang L, Wang Z, Liu X (2014) Development of a collaborative 3D virtual monitoring system through integration of cloud computing and multi-agent technology. Adv Mech Eng 2014(1):1-10

Zhang L, Wang Z, Tan C, Liu X, Feng S (2016) A fruit fly-optimized Kalman filter algorithm for pushing distance estimation of a hydraulic powered roof support through tuning covariance. Appl Sci 6(8):299. https://doi.org/10.3390/app6100299

Zhang L, Zhou X, Wang Z, Tan C, Liu X (2017a) A nonmodel dualtree wavelet thresholding for image denoising through noise variance optimization based on improved chaotic drosophila algorithm. Int $\mathrm{J}$ Pattern Recognit. https://doi.org/10.1142/ S0218001417540143

Zhang XH, Chen L, Liu L et al (2017b) Training method of virtual training system for cantilever type road header. C.N. Patent 201611088154.6, Jan. 25

Zhou X (2014) Research on the key technologies of cooperative control for equipments in the fully mechanized coal face. China University of Mining and Technology, Xuzhou, pp 74-96

Zhou X, Wang Z, Tan C, Ji R, Liu X (2015) A novel approach for shearer memory cutting based on fuzzy optimization method. Adv Mech Eng. https://doi.org/10.1155/2013/319272 